Journal of

Human Nutrition

and Dietetics

\title{
Birthweight, HIV exposure and infant feeding as predictors of malnutrition in Botswanan infants
}

\begin{tabular}{|r|l|}
\hline Journal: & Journal of Human Nutrition and Dietetics \\
\hline Manuscript ID & JHND-17-06-0229-OR.R1 \\
\hline Manuscript Type: & Original Research \\
\hline Section: & Public Health and Epidemiology \\
\hline \multicolumn{3}{c}{} \\
\multicolumn{3}{c}{ SCHOLARONE } \\
\multicolumn{3}{c}{ Manuscripts } \\
\end{tabular}

Journal of Human Nutrition and Dietetics 
1 Main Document

2

3 Title

4 Birthweight, HIV exposure and infant feeding as predictors of malnutrition in Botswanan infants 5

6 Key words: child undernutrition, malnutrition, HIV, infant feeding practices, 1000 days, 7 Botswana

\section{Abstract}

Background: A better understanding of the nutritional status of infants who are HIV-ExposedUninfected (HEU) and HIV-Unexposed-Uninfected (HUU) during their first 1000 days is a key to improving population health, particularly in sub-Saharan Africa.

Methods: A cross-sectional study compared nutritional status, feeding practices and determinants of nutritional status of HEU and HUU infants residing in representative selected districts in Botswana during their first 1000 days of life. Four hundred and thirteen infants $(37.3 \% \mathrm{HIV}$ exposed), aged 6-24 months attending routine child health clinics were recruited. Anthropometric, 24-hour dietary intake and socio-demographic data was collected. Anthropometric $z$-scores were calculated using 2006 WHO growth standards. Modelling of the determinants of malnutrition was undertaken using logistic regression.

Results: Overall, prevalence of stunting, wasting and underweight were $10.4 \%, 11.9 \%$ and $10.2 \%$ respectively. HEU infants were more likely to be underweight $(15.6 \%$ vs. $6.9 \%),(\mathrm{p}<0.01)$ and stunted $(15.6 \%$ vs. $7.3 \%),(p<0.05)$ but not wasted $(p=0.14)$ than HUU infants. HEU infants tended to be formula fed (89.4\%) whereas HUU infants tended to breastfeed (89.6\%) for the first six months $(\mathrm{p}<0.001)$. Significant predictors of nutritional status were HIV exposure, birthweight, birth length, Apgar score and mother/caregiver's education with little influence of socioeconomic status.

Conclusions: HEU infants aged 6-24 months had worse nutritional status compared to HUU infants. Low birthweight was the main predictor of undernutrition in this population. Optimisation of infants' nutritional status should focus on improving birthweight. In addition, specific inteverntions should target HEU infants in order to eliminate growth disparity between HEU and HUU infants. 


\section{Introduction}

Globally, under-five mortality declined from 90 to 43 deaths per 1000 live births between 1990 and $2015^{(1)}$. However, in sub-Saharan Africa under-five mortality still remains higher at 86 deaths per 1000 live births ${ }^{(1)}$. Mortality in children aged less than five years is mainly attributed to undernutrition, with $45 \%$ of these deaths being preventable through optimal nutrition, especially in the first 1000 days (the period from conception to the child's second birthday) ${ }^{(2,3-4)}$.

Human Immunodeficiency Virus/Acquired Immune Deficiency Syndrome (HIV/AIDS) is still a major health challenge in Botswana ${ }^{(5-6)}$. Strategies including, prevention of mother-to-child transmission (PMTCT) of HIV have been highly successful in Botswana, reducing mother-to-child transmission rates to approximately $2.6 \%{ }^{(7-8)}$. Without PMTCT strategies, HIV transmission from mother to child could be as high as $25 \%{ }^{(8)}$. However, this success has resulted in the increase in the population of HIV-exposed but uninfected (HEU) infants. ${ }^{(9-10)}$. Health and/or nutritional issues unique to HEU infants will have major population health implications as their numbers increase ${ }^{(11-}$ ${ }^{12)}$. Currently, the health and nutritional consequences of HIV-exposure are largely under study ${ }^{(10,}$ 12). However, a higher risk for mortality in HEU compared to HIV-unexposed uninfected (HUU) infants has been previously reported ${ }^{(13-16)}$. Risk of mortality can be modified by optimising nutritional status of infants, this requires a good understanding of context specific patterns and determinants of undernutrition in this group ${ }^{(17)}$.

Studies conducted in other African countries comparing the nutritional status of HEU and HUU infants show large variations in the levels of undernutrition ${ }^{(12,18-20)}$. Majority of these studies were conducted before ART was widely available to mothers and infants ${ }^{(12,18-20)}$. In contrast, ART is available to approximately $92 \%$ of pregnant women in Botswana ${ }^{(8)}$. Monitoring and management of infant health and nutrition is intensive and widely accessible ${ }^{(21)}$. The same conditions are often not present in other sub-Saharan African countries with high HIV prevalence. However, the level of mortality in HEU infants in Botswana is comparable or higher than in other sub-Saharan African countries ${ }^{(13)}$. Furthermore, the feeding policy adopted for HEU infants in Botswana is unique, as it has inadvertently undermined breastfeeding levels through provision of free formula ${ }^{(22)}$. Currently, the nutritional status of HEU and HUU in Botswana have not been well documented. Therefore, understanding nutritional status and its determinants between HEU and HUU infants in Botswana is important for informing policies and interventions which can be used to achieve comparable growth between these infants if such differences exist. Thus helping reduce the risk of mortality in HEU infants. This study sought to investigate the patterns of undernutrition per HIV-exposure within 
context of feeding practices in infants aged 6- 24 months in selected districts in Botswana. In addition, this study, also aimed to identify determinants of nutritional status in these infants.

\section{Methods}

\section{Study participants and population}

The study was conducted in Botswana using a comparative cross-sectional study design between December 2014 and February 2015 in 19 different government health facilities of varying sizes (hospital, primary hospital, clinics and/or health posts) located across the four districts (KwenengEast, Kgatleng, Selebi Phikwe and Francistown). Health facilities in districts with high HIV prevalence in the adult population were selected in order to obtain an adequate number of HEU infants. Prevalence of HIV in these districts ranged from $26.3 \%$ in Kweneng East to $39.6 \%$ in Selebi Phikwe They were selected as having higher HIV prevalence than the national average, in order to ensure an appropriate sample of HEU infants. These four districts were selected to represent urban, semi-urban and rural areas. Kweneng-East is mainly rural with some semi-urban locations. Kgatleng is mainly rural, Selebi Phikwe is semi-urban while Francistown is mostly urban. These locations span the eastern hardveld where at least $80 \%$ of the population of Botswana live ${ }^{(23-}$ 24). All caregivers from the general population with infants aged 6-24 months attending their monthly growth monitoring in a health facility, were invited to participate in the study. Eligible caregivers had to be citizens of Botswana, aged over 18 years and were the infant's parent and/or legal guardian. There were no other exclusion criteria. The participants were approached as they arrived at the health facility. Children in Botswana, aged 0-59 months attend routine monthly growth monitoring in government health facilities across the country. When more participants than required showed interest in the study, simple randomisation was used to select participants by allocating each participant a number.

\section{Sample size}

A representative sample of infants in selected districts was stratified according to the population of the infants aged under five years in each district based upon data supplied by the Ministry of Health and Wellness in Botswana (Nutrition and Food Control division). Therefore, a district with a higher number of under-fives had a larger representation within the sample. In addition, the composition of the sample within each district was selected such that it represented the proportions of infants attending each type of health facility (hospital, primary hospital, clinics and/or health posts) within that district. Therefore, a type of health facility receiving a higher number of infants would have a higher share of the sample within each district. 
97

98

99

100

101

102

103

104

105

106

107

108

109

110

111

112

113

114

115

116

117

118

119

120

121

122

123

124

125

126

127

128

129

130

To facilitate a logistic regression analysis, an adequate sample size assuming a medium size relationship between the dependant variables (underweight, stunting and wasting) and independent variables and, $\alpha=0.05$ and $\beta=0.20$ was taken to be $N \geq 50+8 \mathrm{~m}$ (where $\mathrm{m}$ is the number of independent variables) ${ }^{(25)}$. In total, 44 potential independent variables were identified a priori to the data collection; resulting in a minimum sample size of 402 caregiver-infant pairs (see Table S1). In addition, oversampling by $10 \%$ was also employed to counter missing data. Independent variables identified a priori and known to affect undernutrition in infants such as birthweight, sex, and maternal age, care giver education level and socio economic factors were included $\left({ }^{26-28}\right)$. These variables were derived from data collection (anthropometry, dietary recall, interview of caregivers) and review of the child health card. However, due to the cross-sectional nature of the study, maternal nutrition and health variables prior to the study, such as during pregnancy were not available. HIV-exposure was maintained in all analysis as it was a variable of interest.

\section{Procedures}

Participants were recruited during their infant's free monthly routine health check-up at a health facility. In total 419 participants were approached to take part in the study. Five infants with an undocumented HIV status and/or missing PCR DNA/rapid HIV tests were not enrolled into the study. Of all the participants approached, only one declined to take part in the study. The final sample size was, therefore, 413 infants.

Data were collected by the lead author and two trained assistants using a structured interview with the caregiver and review of each child's health card. All caregivers in Botswana are given and keep a health card for their infant at birth. This card contains details such as birthweight and length, vaccinations, monthly weight and feeding practices. HIV-exposure was determined from the child's health card as per the latest DNA/PCR or rapid test result. HIV negative mothers were tested every three months for HIV during antenatal care, with the latest test at 36 weeks documented in the child's health card. Socio-demographic characteristics, feeding practices and health history as potential independent variables were collected from the caregiver and the health card. Anthropometric measures of length/height and weight were measured in duplicate from all the infants as per WHO standard procedure ${ }^{(29)}$ using standardised equipment. Weight was measured to the nearest $0.05 \mathrm{~g}$ using calibrated Seca ${ }^{\circledR}$ Scales 385 and 875 (Seca gmbh \& co, Hamburg, Germany) and length/height was measured to the nearest $1 \mathrm{~mm}$ using Seca ${ }^{\circledR}$ measuring board 417 (Seca gmbh \& co, Hamburg, Germany) and Seca ${ }^{\circledR}$ stadiometre, Seca 217 (Seca gmbh \& co, Hamburg, Germany). Length for age $z$-scores (LAZ), weight for age $z$-scores (WAZ) and weight for length $z$ scores (WLZ) were calculated according to the 2006 WHO child growth standards using the WHO 
131

132

133

134

135

136

137

138

139

140

141

142

143

144

145

146

147

Anthro 2005 programme, Beta version ${ }^{(30)}$. Stunting, underweight and wasting was determined at $z$ score $<-2$ SD based on LAZ, WAZ and WLZ respectively.

A modified USDA five step multiple Pass 24-hour dietary recall protocol ${ }^{(31)}$ was used to measure infant's current nutritional intake as recalled by the caregiver. A similar multiple pass 24-hour dietary recall was validated in Ugandan children and was found to be valid in assessing dietary intake of infants residing in communities with similar diets ${ }^{(32)}$. Dietary diversity was calculated by allocating a score for consumption of food from one of the seven food groups (Grains, roots and tubers: Legumes \& nuts: Dairy products: Flesh foods: Eggs: vitamin A rich fruits and vegetables: other fruits and vegetables) in the preceding 24 hours ${ }^{(33)}$. Therefore, resulting in a maximum possible score of 7 , an infant's diet scoring 4 or more is considered diverse ${ }^{(33)}$. In addition, to dietary diversity ${ }^{(33)}$, Nutritics ${ }^{\odot}$ software ${ }^{(34)}$, was used to derive the energy and protein intake of each infant. Nutritional information of foods consumed was derived from packaging, data from South African Composition Database ${ }^{(35)}$ and McCance and Widdowson's composition of foods databases ${ }^{(36)}$. Cereals such as sorghum and fortified sorghum were consumed by majority of infants but nutritional content was not available. Therefore, cooked samples of these were weighed, frozen then freeze dried and analysed in the laboratory for protein per 100 grams using the Flash EA1112 nitrogen elemental analyser (Soeks FL 33334, USA). Energy per 100 grams was analysed using Parr 6300 Oxygen bomb calorimetre (Parr Instrument Co., Moline, Illinois, USA).

Data was entered into SPSS version 22 software ${ }^{(37)}$ for analysis and $10 \%$ of this data was randomly selected using a computer number generator and then screened for accuracy by the co-authors.

\section{Ethics}

Ethical approval was received both from the University of Nottingham's Medical School Research Ethics Committee and the Health Research and Development Committee in Botswana. Informed consent was obtained from all caregivers. The two assistants were trained in seeking informed consent. When inappropriate feeding and/or malnutrition were identified the caregiver was briefly counselled by the lead author, who is also a registered dietitian. The caregiver was then referred to the health facility for further follow-up and this was documented in the child's health card to ensure continuity of care.

\section{Statistical methods}

Data was analysed using Statistical Package for Social Sciences, SPSS version $22^{(37)}$. A casecontrol analysis approach was employed where HEU and HUU infants were compared for outcomes of interest. Baseline data is described as per HIV exposure. Chi square, was used to test for proportions between the two groups (HEU and HUU infants) to determine prevalence of 
164

165

166

167

168

169

170

171

172

173

174

175

176

177

178

179

180

181

182

183

184

185

186

187

188

189

190

191

192

193

194

195

196

underweight, wasting and stunting. Continuous variables were analysed using Kolgorov-Smirnov test to determine whether the distribution was Gaussian or not. Independent samples t-test or Mann-Whitney $U$ test were used to test for differences between the two groups for parametric and non-parametric variables respectively. Variation of the mean was presented as standard deviation. Forward logistic regression was performed to determine predictors of stunting, underweight and wasting. The threshold for introducing the variables into the logistic regression model was set at $\mathrm{p}$ $<0.1$. Cases with missing values for some of the independent variables were excluded. On this basis $86.2 \%$ of cases with no missing values were included in the analysis for each of the three dependent variables (stunting, underweight and wasting). Variables with missing data included feeding method at $<6$ months (2.6\%), feeding method at 6-12 months (6.1\%), birthweight (4.1\%), Apgar score $(2.9 \%)$, and age at which complementary feeds were introduced $(2.4 \%)$. One of the co-authors (JAS) had the overall oversight of the statistical methods and analysis. Statistical significance was taken at $\mathrm{p}<0.05$ in all analysis.

\section{Results}

\section{Characteristics of participants}

A total of 413 participants were recruited, of which 154 were HEU (37.3\%) and 259 were HUU (62.7\%). Table 1 shows the characteristics of participants by HIV exposure. No significant differences were found between HEU and HUU infants in terms of age, proportions of sex, birthweight or length nor birthweight classification. However, HEU infants had significantly more siblings compared to HUU infants $(\mathrm{p}<0.001)$. In addition, HEU infants were more likely to have had a sibling who died compared to HUU infants $(\mathrm{p}<0.05)$.

As shown in Table 1, HIV positive mothers tended to be older at the time of the infant's birth $(\mathrm{p}<0.001)$. In addition, the primary caregivers of HEU infants had significantly lower education levels $(\mathrm{p}<0.001)$. No significant differences were found in other mother/caregiver and household characteristics between the two groups.

\section{Feeding practices}

Table 2 shows feeding practices of infants per HIV-exposure from birth to age at time of data collection. These feeding practices were self-reported by the caregiver and corroborated using data from each child's health card, where possible. HEU infants were more likely to be formula fed from birth and at 6-12 months compared to HUU infants $(\mathrm{p}<0.001)$. The remainder of the infants $(n=11)$ not breastfeeding or formula feeding in the first twelve months were taking cow's milk. Of those infants aged more than 12 months, it was found that HUU infants were more likely to be breastfed compared to their HEU counterparts $(\mathrm{p}<0.001)$. Overall the energy and protein intake for male and 
female HEU and HUU infants were higher than recommended nutrient intakes (RNI for infants aged 1-3 years). Average energy and protein intake was found to be higher in HEU compared to HUU infants for females and vice versa for males. However, both these differences did not reach statistical significance. In addition, there were no significant differences between HEU and HUU infants in age at which the infant was introduced to complementary feeds. Dietary diversity was low for all infants, and there was no significant difference between HEU and HUU infants.

\section{Nutritional outcomes}

The prevalence of underweight was higher in HEU infants (Table 3; $<<0.01$ ). In addition, HEU infants also had significantly higher prevalence of stunting compared to HUU infants (15.6\% vs. 7.3 $\%, \mathrm{p}<0.05)$. Wasting prevalence was higher in HEU infants; however this did not reach statistical significance $(\mathrm{p}=0.14)$.

\section{Determinants of nutritional status}

The results of logistic regression to identify the determinants of underweight, stunting and wasting are shown in Tables 4, 5 and 6. Table 4 shows the determinants of underweight. The analysis revealed that infants living in homes where a child had previously died were over three times more likely to be underweight (adjusted OR 3.205, 95\% CI 1.097- 9.362). However, a higher birthweight or birth length was negatively associated with underweight ( $<<0.001, p=0.03$ respectively). Each kilogram higher weight reduced risk of underweight by $82 \%$ (OR $0.182,95 \%$ CI $0.073-0.450$ ). Similarly, a $1 \mathrm{~cm}$ increase in birth length reduced risk by 10\% (OR 0.899, 95\% CI $0.818-0.988$ ). Importantly, HIV exposure, infant nutrient intakes, maternal and household factors were not associated with risk of underweight. Predictors for stunting as shown in Table 5, were consistent with the simple chi square analysis of prevalence. HEU infants were found to be more than twice as likely to be stunted compared to HUU infants (adjusted OR 2.361, 95\% CI 1.105 -5.046). In addition, a lower level of mother/caregiver's education, and lower birthweight was associated with stunting. Again, nutrient intakes and other maternal and household factors were not significantly associated with risk of stunting. Wasting was more likely in infants with a high Apgar score, however residing in Kweneng East district (rural/semi urban) and having a higher birthweight was negatively associated with wasting. Each kilogram extra weight at birth reduced risk of wasting by 58\% (adjusted OR 0.423, 95\%CI 0.205-0.872). HIV exposure, infant nutrient intake and other household and maternal factors were not significantly associated with risk of wasting. 


\section{Discussion}

229

230

231

232

233

234

235

236

237

238

239

240

241

242

243

244

245

246

247

248

249

250

251

252

253

254

255

256

257

258

259

260

261

Our study has demonstrated that HEU infants aged 6-24 months have poor nutritional outcomes compared to HUU infants. This has implications for policy and programming because currently prevention of mother-to-child transmission of HIV in HEU infants is prioritised over achieving optimal nutritional status. This has inadvertently resulted in inequitable growth between HEU and HUU infants. Data from 154 HEU infants and 259 HUU infants living in selected districts in Botswana demonstrated that HEU infants had higher prevalence of underweight and stunting. HEU infants were also more likely to formula feed in their first 12 months of life whereas HUU infants were more likely to breastfeed. Low birthweight was the strongest predictor of undernutrition in addition to HIV exposure, birth length, mother/care giver's education level, high Apgar score and residing in Kweneng East.

Prevalence of undernutrition in this study was higher in HEU infants compared to HUU infants during their first 1000 days. This is consistent with findings from a number of studies conducted in Zambia, Kenya, South-Africa, Uganda and Tanzania which have demonstrated that HEU infants have poor growth compared to HUU infants ${ }^{(9,12,20,38-39)}$. A study in Kenyan infants found that HEU infants had poor nutritional outcomes especially very high levels of stunting by 24 months ${ }^{(12)}$. Prevalence of stunting in our study between HEU and HUU infants was similar to one found in a study of Ugandan infants enrolled in the PMTCT program ${ }^{(20)}$. Our bivariate analysis of the prevalence of stunting and underweight between HEU and HUU infants is therefore consistent with the larger body of literature. However, other studies conducted in sub-Saharan Africa did not find any differences in nutritional outcomes between HEU and HUU infants ${ }^{(19,40-41)}$. It was found that HEU infants though born slightly smaller compared to HUU infants, were able to quickly catch up in weight and length ${ }^{(19,41-42)}$. This lack of difference in growth patterns was attributed to higher levels of breastfeeding and/or effective counselling for feeding choices in HEU infants ${ }^{(19,41)}$. In the current study HEU infants were more likely to be formula fed than breastfed compared to HUU infants. This may have contributed to their poor growth compared to HUU infants, since poor growth is linked to no or sub-optimal breastfeeding ${ }^{(38,43)}$. It is important to note that our regression modelling indicated that mode of feeding in the first year of life, was not a statistically significant predictor of undernutrition. However, these studies were conducted before ART was widely available to HIV positive women, therefore this may have resulted in no difference in growth between HEU and HUU infants ${ }^{(19,41-42)}$. Other feeding practices such as age of introduction of complimentary feeding (weaning), average energy and protein intake and dietary diversity were not significantly different between HEU and HUU infants. Dietary diversity was poor in both groups of infants because majority of infants did not consume a variety of foods in the 24 hours preceding the 
262 study. Dietary diversity is an important indicator of the quality of the diet as opposed to the quantity 263 of the food served $(26,33)$.

264 HEU infants in this study were vulnerable to poorer nutritional outcomes, especially stunting 265 266 267 because even after adjusting for other variables, HIV-exposure remained a strong predictor for stunting. This finding is consistent with results from a number of studies ${ }^{(18,44-45)}$. A study, conducted in Tanzania found a lower length for age in HEU compared to HUU infants at three and six months ${ }^{(44)}$. A higher risk of stunting in HEU compared to HUU infants has serious implications because stunting is associated with poorer psychomotor and mental development in HEU infants (45). This may affect the future potential development of these infants, especially if stunting is not reversed within the first 1000 days ${ }^{(46-48)}$. Factors such as exposure to ART during pregnancy, poor sanitation and infections in infants especially diarrhoea may account for the increased risk of stunting in HEU compared to HUU infants ${ }^{(26,46)}$. In studies where poor growth was associated with HIV-exposure it was found that HEU infants had lower birthweight compared to HUU infants ${ }^{(14,18 \text {, }}$ 40). In the current study, HEU infants had lower birthweight compared to HUU infants, however this did not reach statistical significance. This is in contrast with a number of studies where HEU infants are more likely to be smaller at birth compared to HUU infants $(49,11,44,46)$. Interestingly, low birthweight was a strong and consistent predictor for poor nutritional status (underweight, stunting and wasting). Infants with low birthweight tend to be more vulnerable to poor nutrition and/or diseases effect ${ }^{(14,18)}$. The findings of the current study show that birthweight is a more powerful predictor of later nutritional status than nutrient intakes from complementary feeds, breastmilk versus formula feeding, household and environmental factors including number of people living in a household, primary water source and income level. Even though birth length was not significantly lower in HEU compared to HUU infants, birth length remained a predictor for underweight, indicating that a lower birth length increased the risk of underweight in these infants. This is consistent with findings from some studies where birth length is a significant intermediary of growth in infants ${ }^{(44,49-50)}$.

Consistent with a number of studies it was found that mother/care giver's education level was a predictor for stunting after adjustment for other variables ${ }^{(26,12,18,51)}$. In addition, HIV positive mothers were significantly older than HIV negative mothers. Younger age and higher education level are associated with better nutritional outcomes because these caregivers tend to have more knowledge about optimal feeding, hygiene and child caring practices ${ }^{(12,18,51-52)}$. These caring practices may especially be relevant in settings where HEU infants tend to formula feed ${ }^{(18)}$. It was also found that HEU infants had significantly more siblings than HUU infants. A higher number of siblings is associated with poor nutritional outcomes in children ${ }^{(53)}$. Although growing up in a 
296 household where another child had died was a significant predictor of the risk of underweight in 297 univariate analysis, after adjusting for potential confounding factors there was no relationship 298 between the number of deceased siblings and risk of stunting, wasting or underweight.

299 Other determinants of nutritional outcomes in these infants included residing in Kweneng East 300 district and Apgar score. Infants who resided in Kweneng East had a lower risk of wasting 301 compared to those in other districts. It is should be noted that Kweneng East district was the only 302 district where growth and health monitoring services were still offered in the main and primary 303 hospital. Other districts have moved these services to smaller clinics and/or health posts. Therefore, 304 infants in Kweneng East district may have benefited from having close access to a multidisciplinary 305 team of health professionals such as paediatricians and dietitians. These health-care workers are not 306 typically accessible in smaller clinics. Accessibility to specialised care is highly relevant to 307 wasting because wasting is an acute form of undernutrition, characterised by rapid weight loss due 308 to acute inadequate intake and/or disease ${ }^{(54)}$. Therefore, infants in Kweneng East district were more 309 likely to have accessed swift and specialised care upon being diagnosed with wasting compared to 310 other districts. A higher Apgar score increased the risk of wasting in these infants almost two-fold. 311 This was not expected because a higher Apgar score is associated with better nutritional outcomes $312{ }^{(55)}$. However, a study in Asian Indian infants found that Apgar is a poor prognosis for growth and 313 development in infants ${ }^{(56)}$.

314 It is important to note the following limitations about the current study. We have only considered 315 the impact of HIV exposure, infant feeding, maternal and household factors upon nutritional status 316 using the extreme outcome measures of stunting, wasting and underweight as determined by 317 anthropometry and reference to WHO cut-offs for $z$ scores. Indices such as micronutrient 318 deficiencies were not included and we also did not focus on lower variance from cutoffs in terms of 319 growth. Contribution of HIV-exposure may be greater at these subclinical levels and thus the $z$ 320 scores may be lower in HEU compared to HUU infants. Due to the cross-sectional study design, we 321 did not have access to maternal nutrition and health indicators variables such as weight, height, 322 CD4 count and use of ART pre-and post-natally. There is also a possibility, albeit a limited one, 323 that some of the infants who were classified as HEU may have been HIV-infected after 6 weeks, 324 since testing of HIV in these infants in Botswana is done at 6 weeks, post weaning if the mother 325 was breastfeeding (6 months) and at 18 months. Some of the infants in our study were not yet 18 326 months, at the time of data collection. However, a majority of these infants were formula feeding, 327 therefore it was highly unlikely that they would have seroconverted. The parity of the mother was 328 not considered in logistic regression. In addition, we have to acknowledge the cross-sectional nature 329 of this study especially in regards to HIV-exposure and nutritional outcomes. Longitudinal studies 
330 are therefore required to elicit more data which will allow us to disentangle feeding modalities from

331 HIV-exposure and also to derive more information on maternal nutrition and health during 332 pregnancy.

333 PMTCT strategies in Botswana needs to be refined, so that optimal nutritional outcomes in HEU 334 infants are prioritised in addition to prevention of MTCT of HIV. This can be achieved by 335 integrating nutrition-specific and -sensitive interventions into this program. This will ensure 336 equitable and optimal growth in HEU and HUU infants during their first 1000 days. Botswana as a 337 country in terms of its health care system infrastructure, PMTCT strategies and growth surveillance 338 for infants is in a good position to effect these significant changes, and thus improve population 339 health.

340 In Botswana, HEU infants aged 6-24 months have poor nutritional status compared to HUU infants. 341 Although mode of feeding was not a statistically significant factor determining risk of 342 undernutrition, HEU infants tended to formula feed while HUU infants tended to breastfeed for the 343 first twelve months of life. Therefore, HEU infants are missing out on the well documented benefits 344 of breastfeeding. In order to increase breastfeeding levels in HEU infants there is need to review the 345 current Botswana government's infant feeding policy in order to align with the new 2016 346 recommendations by WHO. Furthermore, this study demonstrated that the strongest predictor of 347 nutritional outcomes is birthweight, therefore strategies designed to optimise infants' nutritional 348 status in the first 1000 days should aim to improve birthweight.

350 Running title

351 HIV-exposure and nutritional status in infants.

353 Word count

354 Abstract: 249 words

355 Main Body: 4748 words

356 Number of references: 56

357 Number of tables: 6

358 Supplementary table: 1

359 Number of figures: 0

360 Transparency Declaration 
361 The lead author confirms that the manuscript is an honest, accurate and transparent account of the

362 study being reported and that no important aspects of the study have been omitted and that any

363 discrepancies from the study as planned have been explained. The reporting of this work is

364 compliant with STROBE guidelines.

365

366

\section{References}

367

1. WHO, World Health Organisation (2015). Global Health Observatory data repository (1990-

368 present). http://www.who.int/gho/child_health/en/ (accessed $25^{\text {th }}$ April 2016).

369

370

371

372

373

374

375

376

377

2. Black RE, Victoria CS, Walker SP et al. Maternal and child undernutrition and overweight in low-income and middle income countries. Lancet. 2013; 382: 427- 451.

3. Morris SS, Cogill B, Uauy R et al. Effective international action against undernutrition: why has it proven so difficult and what can be done to accelerate progress? Lancent. 2008; 371: 608-621.

4. Victoria GS, Onis de M, Hallal PC et al. Worldwide timing of growth faltering: revisiting implications for interventions. Paediatr. 2010; 125: 473- 480.

5. WHO, World Health organisation (2016). Botswana Statistics Summary (2000- present). http://apps.who.int/gho/data/node.country.country-BWA (accessed 25 ${ }^{\text {th }}$ April 2016).

6. CSO, Central Statistics Office Botswana (2013). Botswana Aids Impact Survey IV (BAIS IV). Gaborone, Botswana.

7. MOH, Ministry of Health Botswana (2012). Botswana National HIV and AIDS Treatment Guidelines. Gaborone, Botswana.

8. UNAIDS (2016). Global plan: on the fast track to an AIDS-free generation. Geneva, Switzerland.

9. Rosala-Hallas A, Bartlett JW, Filteau S. Growth of HIV-exposed uninfected compared with HIV-unexposed, Zambian children: Longitudinal analysis form infancy to school age.BMC Paedtr. 2017; 17:80.

10. Filteau S. The HIV-exposed, uninfected African child. Trop Med and Inter Health. 2009; 14 (3): 276-287.

11. McGrath CJ, Nduati R, Richardson BA et al. The prevalence of stunting is high in HIV-1 exposed uninfected infants in Kenya. J Nutr. 2012; 142: 757 - 763.

12. Rollins NC, Ndirangu J, Bland RM et al. Exclusive breastfeeding, diarrhoeal morbidity and all-cause mortality in infants of HIV-infected and HIV uninfected mothers: an intervention cohort study in Kwazulu Natal, South Africa. Plos ONE. 2013; 8 (12): 1-10. 
394

395

396

397

398

399

400

401

402

403

404

405

406

407

408

409

410

411

412

413

414

415

416

417

418

419

420

421

422

423

424

425

426

13. Shapiro RL, Lockman S, Kim S et al. Infant morbidity, mortality, and breast milk immunologic profiles among breast-feeding HIV -infected and HIV-Uninfected women in Botswana. J Infec Dis. 2007; 196:562 -569.

14. Marinda E, Humphrey JH, Iliff PJ et al. Child Mortality According to Maternal and Infant HIV Status in Zimbabwe. Paed Infec Dis J. 2007; 26: 519 -526.

15. Brahmbhatt H, Kigozi G, Wabwire-Mangen, F et al. Mortality in HIV-Infected and Uninfected Children of HIV-Infected and Uninfected Mothers in Rural Uganda. J Acquir Immune Defic Syndr. 2006; 41: 504-508.

16. Taha TE, Kumwenda NI, Broadhead RL et al. Mortality after the first year of life among human immunodeficiency virus type 1-infected and uninfected children. Paed Infec Dis J. 1999; 18 (8): 689-694.

17. UNICEF, United Nations Children's Fund (2013). Improving Child Nutrition: the achievable imperative for global progress. Report number: E.13.XX.4. New York: UNICEF.

18. McDonald CM, Kupka R, Manji KP et al. Predictors of stunting, wasting and underweight among Tanzanian children born to HIV-infected women. HEUrop J Clin Nutr. 2012; 66:1265 - 1276.

19. Patel D, Bland R, Coovadia H et al. Breastfeeding, HIV status and weights in South African Children; a comparison of HIV-exposed and unexposed children. AIDS. 2010; 24:437 -445.

20. Magezi SR, Kikafunda J, Whitehead R. Feeding and nutritional characteristics of infants on PMTCT programs. J Trop Paedtr. 2008; 55(1): 32-35.

21. Nnyepi M, Gobotswamang KSM, Codjia P. Comparison of estimates of malnutrition in children aged $0-5$ years between clinic based nutrition surveillance and national surveys. $\mathrm{J}$ Public Health Policy. 2011; 32: 281 - 282.

22. Chopra M and Rollins N. Infant feeding in time of HIV: rapid assessment of infant feeding policy and programmes in four African countries scaling up prevention of mother to child transmission programmes. Arch Dis Child. 2008; 93:288-291.

23. CSO, Central Statistics Office. (2015). Botswana. Population census atlas 2011. Gaborone, Botswana.

24. Botswana Tourism. (2013). Botswana Location. http://www.botswanatourism.co.bw/location . (accessed April 2017). 
427 25. Green SB. How many subjects does it take to do a regression analysis? Multi Behavr

428

429

430

431

432

433

434

435

436

437

438

439

440

441

442

443

444

445

446

447

448

449

450

451

452

453

454

455

456

457

458

Research.1991; 26: 449-510.

26. Kimani-Murage EW, Norris SA, Pettifor JM, et al. Nutritional status and HIV in rural South African children. BMC Paedtr. 2011; 11: 1471 - 2431.

27. Akombi BJ, Agho AE, Merom D et al. Multilevel analysis of factors associated with wasting and underweight among children under-five years in Nigeria. Nutrients. 2017; 9 (44): $1-17$.

28. Mbwana HA, Kinabo J, Lambert $\mathrm{C}$ et al. Factors influencing stunting among children in rural Tanzania: an agro-climatic zone perspective. Food Sec. 2017; 1-17.

29. WHO-World Health Organisation (2009). WHO child growth standards and the identification of severe acute malnutrition in infants and children. Geneva: WHO

30. WHO, World Health Organisation (2005). WHO Anthro (version 3.2.2, January 2011) and macros. Geneva, Switzerland.

31. Raper N, Perloff B, Ingwersen L et al. An overview of USDA's dietary intake data system. J Food Comp Analysis. 2004; 17: 545-555.

32. Nightingale H, Walsh KJ, Oluput-Oluput P et al. Validation of triple pass 24-hour dietary recall in Ugandan children by simultaneous weighed food assessment. BMC Nutr. 2016; 2 (56): 1-9.

33. WHO, World Health Organisation (2008). Indicators for assessing infant and young child feeding. Geneva, Switzerland.

34. Nutritics. Released 2011. Nutritics Professional Nutrition Analysis Software. Ireland.

35. SA FOODS (2015). South African Food Data System. http://safoodsapps.mrc.ac.za/foodcomposition// (accessed $24^{\text {th }}$ February 2016).

36. Finglas PM, Roe MA, Pinchen HM et al. (2014) McCance and Widdowson's The Composition of Foods. Seventh summary edition. Cambridge: Royal Society of Chemistry.

37. IBM Corp. Released 2013. IBM SPSS Statistics for Windows. Version 22.0. Armonk, NY: IBM Corp.

38. Arpadi S, Fawzy A, Aldrovandi GM et al. Growth faltering due to breastfeeding cessation in uninfected children born to HIV-infected mothers in Zambia. Am J Clin Nutr. 2009; 90:344 -353 .

39. Bandara T, Hettiarachchi M, Liyanage $C$ et al. current infant feeding practices and impact on growth in babies during the second half of infancy. J Hum Diet. 2015; 28:366-374. 
459 40. Sherry B, Embree JE, Mei Z et al. Sociodemographic characteristics, care, feeding practices, 460 and growth of cohorts of children born to HIV-1 seropositive and seronegative mothers in 461 Nairobi, Kenya. Tropic Med Inter Health. 2000; 5 (10): 678-686.

462 463 464 465 466 467 468 469 470

41. Bailey R.C, Kamenga MC, Nsuami MJ et al. Growth of children according to maternal and child HIV, immunological and disease characteristics: a prospective cohort study in Kinshasa, Democratic Republic of Congo. Inter Epidem Assoc.1999; 25: 532-540.

42. Isanaka S, Duggan C, Fawzi WW. Patterns of postnatal growth in HIV-infected and HIV exposed children. Nutr Reviews. 2009; 67 (6): 343-359.

43. Coovadia HM. \& Bland RM. Preserving breastfeeding practice though the HIV pandemic. Tropic Med and Inter Health. 2007; 12: 1116-1133.

44. Wilkinson AL, Pedersen SH, Urassa M et al. Associations between gestational anthropometry, maternal HIV, and fetal and early infancy growth in a prospective rural/semi-rural Tanzanian cohort, 2012-13. BMC Preg Childbirth.2015; 15 (277): 1-13.

45. McDonald CM, Manji KP, Kupka R et al. Stunting and wasting are associated with poorer psychomotor and mental development in HIV-exposed Tanzanian infants. J Nutr. 2013; 143: 204-214.

46. Makasa M, Kasonka L, Chisenga M et al. Early growth of infants of HIV-infected and uninfected Zambian women. Trop Med Inter Health. 2007; 12 (5): 594-601.

47. Leroy JL, Ruel M, Habicht JP et al. linear growth deficit continues to accumulate beyond the first 1000 days in low- and middle-income countries: global evidence from 51 national surveys Nutr. 2014; 144: 1460-1466.

48. Victoria GC, de Onis M, Hallal PC et al. Worldwide timing of growth faltering: revisiting implications for interventions. Paedtr. 2010; 125 (3): 473-483.

49. Powis KM, Smeaton L, Hughes MD et al. In-utero triple antiretroviral exposure associated with decreased growth among HIV-exposed uninfected infants in Botswana. AIDS. 2016; 30:211-220.

50. Sudfeld CR, Quanhong L, Chinyanga Y et al. Linear growth faltering among HIV-exposed uninfected children AIDS.2017; 73 (2): 182-189.

51. Abuya BA, Ciera J. \& Kimani-Murage E. Effect of mother's education on child's nutritional status in the slums of Nairobi. BMC Paedtr 2012; 12 (80): 1-10

52. Huynh D.T.T, Estorninos E, Capeding R.Z et al. Longitudinal growth and health outcomes in nutritionally at-risk children who received long-term nutritional intervention. J Hum Nutr Diet. 2015; 28:623-635.

53. Biswas S. \& Bose K. Effect of number of rooms and sibs on nutritional status among rural Bengalee preschool children from eastern India. Coll Antropol. 2011; 35:1017-1022. 
494 54. WHO, World Health Organisation (2017).

495 http://www.who.int/nutrition/topics/moderate_malnutrition/en/ . (accessed April 2017)

496

497

498

55. Trivedi DJ, Shindhe V, Rockhade CJ. Influence of maternal nutrition during pregnancy on developmental outcome in first 30 days of independent neonatal life. Inter J Clin Biochem Research. 2016; 3(4): 371-375.

499

500

56. Lee $\mathrm{CH}$, Ramachandran $\mathrm{P}$, Madan A et al. Morbidity risk at birth fir Asian Indian small for gestational age infants. Am J Public Health.2010; 100 (5): 820-822.

501

14

15

16

17

18

19

20

21

22

23

24

25

26

27

28

29

30

31

32

33

34

35

36

37

38

39

40

41

42

43

44

45

46

47

48

49

50

51

52

53

54

55

56

57

58

59

60 
Table 1: Characteristics of HEU and HUU infants from selected districts in Botswana $(\mathrm{N}=413)$

\begin{tabular}{|c|c|c|c|c|}
\hline Characteristic & Total $(\mathrm{N}=413)$ & HEU infants $(n=154)$ & HUU infants $(n=259)$ & P-value \\
\hline \multicolumn{5}{|l|}{ Infant's characteristics } \\
\hline Age in months [Median,(IQR) $]^{1,3}$ & $14.00(9.00)$ & $14.00(9.00)$ & $14.00(9.00)$ & 0.96 \\
\hline \multicolumn{5}{|l|}{$\operatorname{Sex}[\%]^{2}$} \\
\hline Females & 52.3 & 50.6 & 53.3 & 0.68 \\
\hline Males & 47.7 & 49.4 & 46.7 & \\
\hline Birthweight in $\mathrm{Kg}[\mathrm{Mean} \pm \mathrm{SD}]^{3}$ & $3.01 \pm 0.47$ & $2.96 \pm 0.50$ & $3.03 \pm 0.46$ & 0.15 \\
\hline Birth Length in cm $[\text { Mean } \pm \mathrm{SD}]^{3}$ & $50.01 \pm 3.87$ & $49.71 \pm 3.96$ & $50.19 \pm 3.80$ & 0.23 \\
\hline \multicolumn{5}{|l|}{ Birthweight classification [\%] ${ }^{2}$} \\
\hline Low: $\quad<2.5 \mathrm{Kg}$ & 2.1 & 12.3 & 12.1 & 1.00 \\
\hline Normal: $\geq 2.5 \mathrm{~kg}$ & 87.4 & 87.7 & 87.9 & \\
\hline Number of siblings $[\text { Median, }(\mathrm{IQR})]^{3}$ & $1.00(2.00)$ & $2.00(2.00)$ & $1.00(1.00)$ & $<0.001$ \\
\hline \multicolumn{5}{|l|}{ Siblings who have died? [\%] $]^{2}$} \\
\hline Yes & 7.7 & 11.7 & 5.4 & 0.03 \\
\hline No & 92.3 & 88.3 & 94.6 & \\
\hline \multicolumn{5}{|l|}{ Mother/care-giver's characteristics } \\
\hline Mother's age at birth [Median,(IQR)] & $26.00(9.00)$ & $30.00(8.00)$ & $25.00(7.00)$ & $<0.001$ \\
\hline \multicolumn{5}{|l|}{ Primary care-giver's education level $[\%]^{2}$} \\
\hline $0-7$ years & 9.9 & 17.5 & 5.4 & \\
\hline$\geq 8$ years & 90.1 & 82.5 & 94.6 & $<0.001$ \\
\hline \multicolumn{5}{|l|}{ Primary care-giver's marital status [\%] ${ }^{2}$} \\
\hline Single/widowed/divorced/ other & 79.2 & $76.0 \%$ & 81.1 & 0.27 \\
\hline Married/lives with partner & 20.8 & $24.0 \%$ & 18.9 & \\
\hline
\end{tabular}


Primary care-giver's Employment status [\%] ${ }^{2}$

Not employed

75.8

77.3

74.9

Self-employed

75.8
3.9

77.3

Formally employed

20.3

18.2

3.5

21.6

Primary care-giver's monthly income $[\%]^{2}$

$\begin{array}{ll}0-599 & \text { BWP } \\ 600-999 & \text { BWP }\end{array}$

69.0

5.1
25.9

68.8

$1000+\quad$ BWP

5.8

69

5.1

25.3

25.9

\begin{tabular}{|c|c|c|c|c|}
\hline Characteristics of the household & & & & \\
\hline Number of people in the household [Median,(IQR)] & $6.00(4.00)$ & $6.00(4.00)$ & $6.00(4.00)$ & 0.88 \\
\hline \multicolumn{5}{|l|}{ Primary water source $[\%]^{2}$} \\
\hline Piped & 99.5 & 99.4 & 99.6 & \\
\hline Not piped & 0.5 & 0.6 & 0.4 & 0.71 \\
\hline \multicolumn{5}{|l|}{ Toilet type in homestead [\%] $]^{2}$} \\
\hline Flush & 25.6 & 21.6 & 28 & \\
\hline Pit latrine & 74.4 & 78.4 & 72 & 0.18 \\
\hline
\end{tabular}

\footnotetext{
(1) time of data collection
}

2. Chi square was used to test difference in proportions [\%] between HEU and HUU infants for various variables.

3. Mann-Whitney U test/ t-test was used to test for differences between HEU and HUU infants for non- parametric and parametric variables respectively.

4. $\$ 1=10.30$ BWP (Botswana Pula) at the time of data collection

5. Abbreviations: HEU:HIV-exposed-uninfected, HUU: HIV-unexposed-uninfected; SD: Standard Deviation; IQR: Inter Quartile Range 
Table 2: Feeding practices of infants by HIV exposure from selected districts in Botswana.

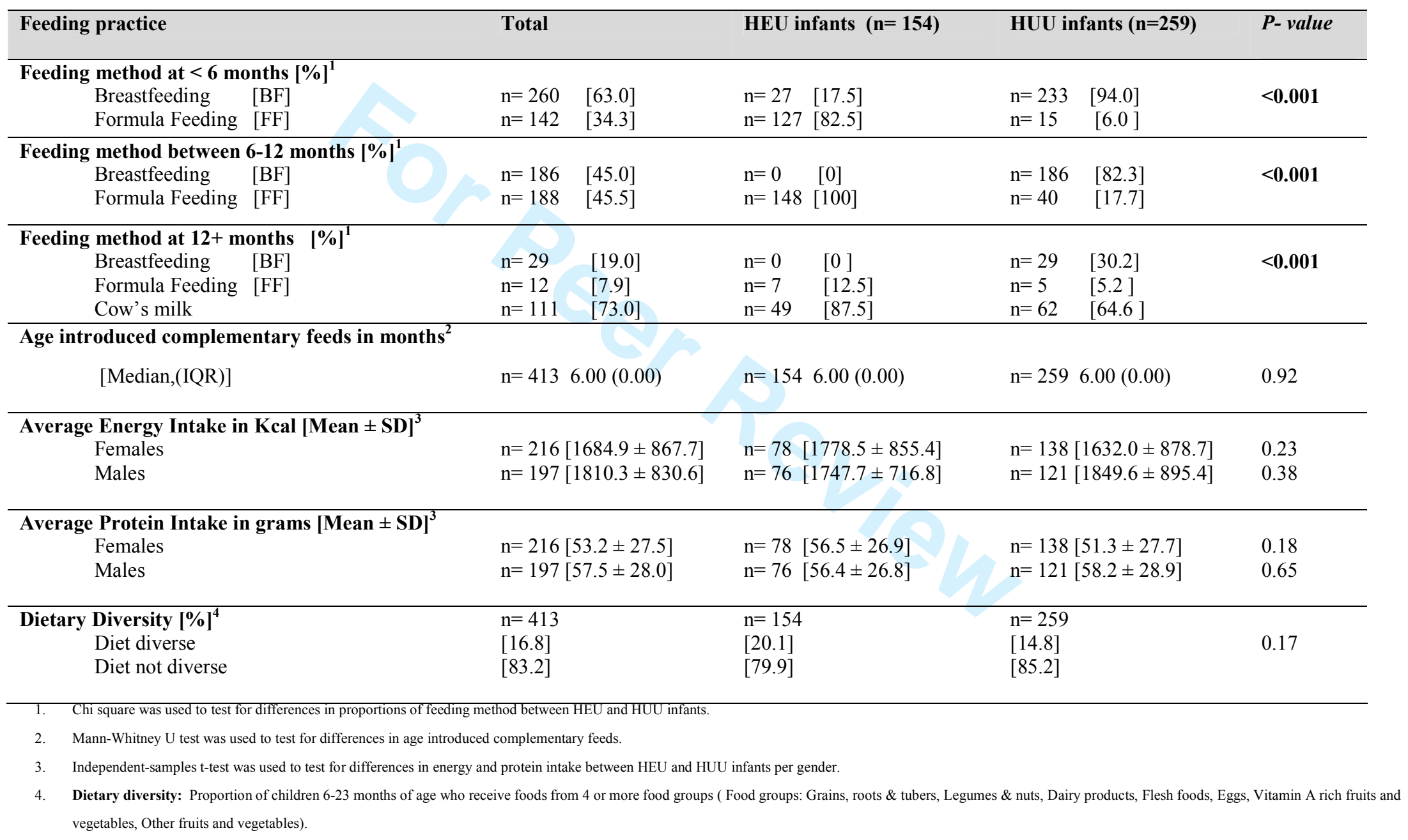


Abbreviations: HEU:HIV-exposed-uninfected, HUU: HIV-unexposed-uninfected; SD: Standard Deviation; IQR: Inter Quartile Range

Table 3: Prevalence of undernutrition in HEU and HUU infants from selected districts in Botswana.

\begin{tabular}{|c|c|c|c|c|}
\hline Nutritional status & Total $(\mathrm{N}=413)$ & HEU infants $(n=154)$ & HUU infants $(n=259)$ & P-value \\
\hline Underweight $[\%]^{1}$ & 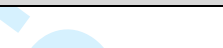 & & & \\
\hline Yes & 10.2 & 15.6 & 6.9 & $<0.01$ \\
\hline No & 89.8 & 84.4 & 93.1 & \\
\hline \multicolumn{5}{|l|}{ Stunting $[\%]^{1}$} \\
\hline Yes & 10.4 & 15.6 & 7.3 & $<0.05$ \\
\hline No & 89.6 & 84.4 & 92.7 & \\
\hline \multicolumn{5}{|l|}{ Wasting [\%] ${ }^{1}$} \\
\hline Yes & 11.9 & 14.9 & 10 & 0.14 \\
\hline No & 88.1 & 85.1 & 90 & \\
\hline
\end{tabular}

2. Abbreviations: HEU: HIV-exposed-uninfected, HUU: HIV-unexposed-uninfected 
Table 4: Logistic regression model of predictors of underweight in infants aged 6-24 months in selected districts in Botswana ( $\mathrm{n}=356$ )

\begin{tabular}{llccccccc}
\hline & & & & & & \multicolumn{2}{c}{ 95\% C.I.for odds ratio } \\
\cline { 5 - 8 } & & B & S.E. & Wald & P-value & Odds ratio & Lower & Upper \\
\hline Step 1 & Birthweight & -2.091 & .410 & 25.981 & .000 & .124 & .055 & .276 \\
& Constant & 3.836 & 1.127 & 11.589 & .001 & 46.346 & & \\
\hline Step 2 & Primary water source & -2.696 & 1.468 & 3.375 & .066 & .067 & .004 & 1.198 \\
& Birthweight & -2.144 & .416 & 26.510 & .000 & .117 & .052 & .265 \\
& Constant & 6.646 & 1.939 & 11.749 & .001 & 769.770 & & \\
\hline Step 3 & Primary water source & -2.689 & 1.456 & 3.412 & .065 & .068 & .004 & 1.179 \\
& Birthweight & -1.694 & .460 & 13.567 & .000 & .184 & .075 & .453 \\
& Birth Length & -.104 & .048 & 4.811 & .028 & .901 & .821 & .989 \\
& Constant & 10.475 & 2.661 & 15.498 & .000 & 35411.123 & & \\
\hline Step 4 & Primary water source & -2.821 & 1.459 & 3.738 & .053 & .060 & .003 & 1.040 \\
& Infant lives in home where a child has died & 1.165 & .547 & 4.537 & .033 & 3.205 & 1.097 & 9.362 \\
& Birthweight & -1.706 & .463 & 13.550 & .000 & .182 & .073 & .450 \\
& Birth Length & -.106 & .048 & 4.902 & .027 & .899 & .818 & .988 \\
& Constant & 10.610 & 2.665 & 15.852 & .000 & 40537.131 & \\
\hline Model 1: $\mathrm{R}^{2}=16.3 \%, \mathrm{X}^{2}=30.25, d \mathrm{f}=1, \mathrm{p}<0.001:$ Model $2: \mathrm{R}^{2}=17.8 \%, \mathrm{X}^{2}=33.03, d \mathrm{f}=2, \mathrm{p}<0.001:$ Model $3: \mathrm{R}^{2}=20.0 \%, \mathrm{X}^{2}=37.46 \mathrm{df}=3, \mathrm{p}<0.001:$ Model $4: \mathrm{R}^{2}=22.0 \%, \mathrm{X}^{2}=41.48, d \mathrm{f}=4, \mathrm{p}<0.001$
\end{tabular}

Other independent variables entered into the model are: HIV exposure, gender, feeding method at $<6$ months, feeding method at 6-12 months, Infant primary care giver, is mother alive?, mother/caregivers education, mother/caregiver's marital status, mother/caregiver's employment status, mother/caregiver's income per month, toilet type in homestead, health facility type, district, consumption of at least one source of iron rich food?, dietary diversity, age in months, APGAR score, age introduced complementary feeds, number of servings of tsabana per week, number of consultations with diarrhoea, number of feeds given yesterday, energy intake, protein intake, mother's age at birth, number of people in household and number of siblings/relatives living with infant aged $<5$ years.

Abbreviations: C.I: Confidence Interval, WAZ: Weight for Age; APGAR (Appearance, Pulse, Grimace, Activity and Respiration). APGAR test is usually given to a baby twice, a minute after birth and then five minutes after birth. 
Table 5: Logistic regression model of predictors of stunting in infants aged 6-24 months in selected districts in Botswana ( $\mathrm{n}=356)$

\begin{tabular}{|c|c|c|c|c|c|c|c|c|}
\hline & & \multirow[b]{2}{*}{ B } & \multirow[b]{2}{*}{ S.E. } & \multirow[b]{2}{*}{ Wald } & \multirow[b]{2}{*}{ P-value } & \multirow[b]{2}{*}{ Odds ratio } & \multicolumn{2}{|c|}{ 95\% C.I.for Odds ratio } \\
\hline & & & & & & & Lower & Upper \\
\hline \multirow[t]{2}{*}{ Step 1} & Birthweight & -1.519 & .393 & 14.945 & .000 & .219 & .101 & .473 \\
\hline & Constant & 2.142 & 1.099 & 3.800 & .051 & 8.516 & & \\
\hline \multirow[t]{3}{*}{ Step 2} & Mother/care giver education & -1.429 & .478 & 8.954 & .003 & .239 & .094 & .611 \\
\hline & Birthweight & -1.588 & .400 & 15.740 & .000 & .204 & .093 & .448 \\
\hline & Constant & 3.563 & 1.228 & 8.417 & .004 & 35.276 & & \\
\hline \multirow[t]{4}{*}{ Step 3} & Mother/care giver education & -1.475 & .481 & 9.410 & .002 & .229 & .089 & .587 \\
\hline & Primary water source & -2.845 & 1.457 & 3.814 & .051 & .058 & .003 & 1.010 \\
\hline & Birthweight & -1.637 & .406 & 16.295 & .000 & .194 & .088 & .431 \\
\hline & Constant & 6.552 & 2.006 & 10.661 & .001 & 700.311 & & \\
\hline \multirow[t]{5}{*}{ Step 4} & HIV exposure & .859 & .388 & 4.913 & .027 & 2.361 & 1.105 & 5.046 \\
\hline & Mother/care giver education & -1.257 & .498 & 6.376 & .012 & .284 & .107 & .755 \\
\hline & Primary water source & -2.797 & 1.441 & 3.769 & .052 & .061 & .004 & 1.027 \\
\hline & Birthweight & -1.637 & .413 & 15.728 & .000 & .195 & .087 & .437 \\
\hline & Constant & 5.902 & 2.025 & 8.499 & .004 & 365.789 & 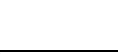 & \\
\hline
\end{tabular}

Other independent variables entered into the model are: gender, feeding method at $<6$ months, feeding method at 6-12 months, Infant primary care giver, is mother alive?, mother/caregiver's marital status,

mother/caregiver's employment status, mother/caregiver's income per month, toilet type in homestead, health facility type, district, does infant live in environment where a child has died?, consumption of at least one source of iron rich food?, dietary diversity, age in months, birth length, APGAR score, age introduced complementary feeds, number of servings of tsabana per week, number of consultations with diarrhoea, number of feeds given yesterday, energy intake, protein intake, mother's age at birth, number of people in household and number of siblings/relatives living with infant aged $<5$ years.

Abbreviations: C.I: Confidence Interval, LAZ: Length for Age; APGAR (Appearance, Pulse, Grimace, Activity and Respiration). APGAR test is usually given to a baby twice, a minute after birth and then five minutes after birth. 
Table 6: Logistic regression model of predictors of wasting in infants aged 6-24 months in selected districts in Botswana ( $\mathrm{n}=356)$

\begin{tabular}{|c|c|c|c|c|c|c|c|c|}
\hline & & \multirow[b]{2}{*}{ B } & \multirow[b]{2}{*}{ S.E. } & \multirow[b]{2}{*}{ Wald } & \multirow[b]{2}{*}{ P-value } & \multirow[b]{2}{*}{ Odds ratio } & \multicolumn{2}{|c|}{ 95\% C.I.for Odds ratio } \\
\hline & & & & & & & Lower & Upper \\
\hline \multirow[t]{2}{*}{ Step 1} & Residing in Kweneng East district & -.908 & .349 & 6.750 & .009 & .404 & .203 & .800 \\
\hline & Constant & -1.596 & .197 & 65.697 & .000 & .203 & & \\
\hline \multirow[t]{3}{*}{ Step 2} & Residing in Kweneng East district & -.924 & .352 & 6.890 & .009 & .397 & .199 & .791 \\
\hline & Birthweight & -.807 & .354 & 5.188 & .023 & .446 & .223 & .894 \\
\hline & Constant & .775 & 1.043 & .553 & .457 & 2.172 & & \\
\hline \multirow[t]{4}{*}{ Step 3} & Primary water source & -2.734 & 1.454 & 3.536 & .060 & .065 & .004 & 1.123 \\
\hline & Residing in Kweneng East district & -1.002 & .361 & 7.679 & .006 & .367 & .181 & .746 \\
\hline & Birthweight & -.834 & .358 & 5.435 & .020 & .434 & .215 & .876 \\
\hline & Constant & 3.588 & 1.848 & 3.768 & .052 & 36.152 & & \\
\hline \multirow[t]{5}{*}{ Step 4} & Primary water source & -2.517 & 1.456 & 2.989 & .084 & .081 & .005 & 1.400 \\
\hline & Residing in Kweneng East district & -1.053 & .365 & 8.332 & .004 & .349 & .171 & .713 \\
\hline & Birthweight & -.860 & .369 & 5.437 & .020 & .423 & .205 & .872 \\
\hline & Apgar score at birth & .582 & .283 & 4.247 & .039 & 1.790 & 1.029 & 3.115 \\
\hline & Constant & -2.106 & 3.330 & .400 & .527 & .122 & & \\
\hline
\end{tabular}

Other independent variables entered into the model are: HIV exposure, gender, feeding method at $<6$ months, feeding method at 6-12 months, Infant primary care giver, is mother alive?, mother/caregivers education, mother/caregiver's marital status, mother/caregiver's employment status, mother/caregiver's income per month, toilet type in homestead, health facility type, district, does child live in environment where a child has died?, consumption of at least one source of iron rich food?, dietary diversity, age in months, birthweight, birth length, age introduced complementary feeds, number of servings of tsabana per week, number of consultations with diarrhoea, number of feeds given yesterday, energy intake, protein intake, mother's age at birth, number of people in household and number of siblings/relatives living with infant aged $<5$ years.

Abbreviations: C.I: Confidence Interval, WLZ: Weight for Length; APGAR (Appearance, Pulse, Grimace, Activity and Respiration). APGAR test is usually given to a baby twice, a minute after birth and then five minutes after birth. 
Supplementary Table 1: Independent variables used in logistic regression model

\begin{tabular}{|c|c|c|c|}
\hline Variable & Definition & Variable type & Data Source \\
\hline \multicolumn{4}{|l|}{ Dependant variables } \\
\hline Wasting & $\begin{array}{l}\text { Yes: } W L Z<-2 \\
\text { No: } W L Z \geq-2\end{array}$ & Categorical & Anthropometric data \\
\hline Stunting & $\begin{array}{l}\text { Yes: } L A Z<-2 \\
\text { No: } L A Z \geq-2\end{array}$ & Categorical & Anthropometric data \\
\hline Underweight & $\begin{array}{l}\text { Yes: } \mathrm{WAZ}<-2 \\
\text { No: } \mathrm{WAZ} \geq-2\end{array}$ & Categorical & Anthropometric data \\
\hline \multicolumn{4}{|l|}{ Independent variables } \\
\hline 1. HIV exposure & $\begin{array}{l}\text { Yes: HEU } \\
\text { No: HUU }\end{array}$ & Categorical & Health card \\
\hline 2. Gender & $\begin{array}{l}0=\text { Females } \\
1=\text { Males }\end{array}$ & Categorical & Health card/interview of caregiver \\
\hline 3. Feeding method at $<6$ months & $\begin{array}{l}0=\text { Formula feeding } \\
1=\text { Breast Feeding }\end{array}$ & Categorical & Health card/interview of caregiver \\
\hline 4. $\quad$ Feeding method 6-12 months & $\begin{array}{l}0=\text { Formula feeding } \\
1=\text { Breast Feeding }\end{array}$ & Categorical & Health card/interview of caregiver \\
\hline 5. Predominant feeding method & $\begin{array}{l}0=\text { Formula feeding } \\
1=\text { Breast Feeding }\end{array}$ & Categorical & Health card/interview of caregiver \\
\hline 6. $\quad$ Child ever breastfed & $\begin{array}{l}0=\mathrm{No} \\
1=\text { Yes }\end{array}$ & Categorical & Health card/interview of caregiver \\
\hline 7. Type of mixed feeding & $\begin{array}{l}0=\text { Formula feeding/other milk } \\
1=\text { Breast Feeding/other milk }\end{array}$ & Categorical & Health card/interview of caregiver \\
\hline 8. Formula feeding frequency appropriate & $\begin{array}{l}0=\mathrm{No} \\
1=\text { Yes }\end{array}$ & Categorical & 24 hour dietary recall \\
\hline 9. Provision of formula & $\begin{array}{l}0=\text { Poor } \\
1=\text { Good }\end{array}$ & Categorical & Health card/interview of caregiver \\
\hline 10. Consumption of at least one source of iron? & $0=\mathrm{No}$ & Categorical & 24 hour dietary recall \\
\hline
\end{tabular}




\begin{tabular}{|c|c|c|c|}
\hline & $1=$ Yes & & \\
\hline 11. Diet diverse? & $\begin{array}{l}0=\text { No } \\
1=\text { Yes }\end{array}$ & Categorical & 24 hour dietary recall \\
\hline 12. Minimum acceptable diet & $\begin{array}{l}0=\text { No } \\
1=\text { Yes }\end{array}$ & Categorical & 24 hour dietary recall \\
\hline 13. Gross development delay at assessment & $\begin{array}{l}0=\mathrm{No} \\
1=\text { Yes }\end{array}$ & Categorical & Assessment/ interview of caregiver \\
\hline $\begin{array}{l}\text { 14. Does the child live in an environment where a } \\
\text { child has died? }\end{array}$ & $\begin{array}{l}0=\text { No } \\
1=\text { Yes }\end{array}$ & Categorical & Interview of caregiver \\
\hline 15. Infant Primary care giver & $\begin{array}{l}\text { Parent (1) vs. Otherwise (0) } \\
\text { Grandmother (1) vs. Otherwise (0) }\end{array}$ & Categorical & Interview of caregiver \\
\hline 16. Is mother alive & $\begin{array}{l}0=\text { No } \\
1=\text { Yes }\end{array}$ & Categorical & Interview of caregiver \\
\hline 17. Caregivers education level & $\begin{array}{l}0=0-7 \text { years } \\
1=\geq 8 \text { years }\end{array}$ & Categorical & Interview of caregiver \\
\hline 18. Caregivers marital status & $\begin{array}{l}0=\text { single } / \text { divorced } / \text { widowed } \\
1=\text { married } / \text { partnered }\end{array}$ & Categorical & Interview of caregiver \\
\hline 19. Caregivers employment status & $\begin{array}{l}\text { Not employed (1) vs. Otherwise }(0) \\
\text { Formally employed vs. Otherwise }(0)\end{array}$ & Categorical & Interview of caregiver \\
\hline 20. Caregivers income per month & $\begin{array}{l}0-599 \mathrm{BWP}^{1}(1) \text { vs. Otherwise }(0) \\
600-999 \mathrm{BWP}^{1} \text { (1) VS. Otherwise }(0)\end{array}$ & Categorical & Interview of caregiver \\
\hline 21. Primary water source & $\begin{array}{l}0=\text { Not-Piped } \\
1=\text { Piped }\end{array}$ & Categorical & Interview of caregiver \\
\hline 22. Toilet type in homestead & $\begin{array}{l}0=\text { Pit latrine } \\
1=\text { Flush }\end{array}$ & Categorical & Interview of caregiver \\
\hline 23. Health facility type & $\begin{array}{l}\text { Hospital/primary hospital (1) vs. Otherwise (0) } \\
\text { Clinic (1) vs. Otherwise (0) }\end{array}$ & Categorical & Observation \\
\hline 24. District & $\begin{array}{l}\text { Kweneng East (1) vs. Otherwise (0) } \\
\text { Francistown (1) vs. Otherwise (0) } \\
\text { Selebi Phikwe (1) vs. Otherwise (0) }\end{array}$ & Categorical & Observation \\
\hline 25. Location type & $\begin{array}{l}\text { Rural (1) vs. Otherwise (0) } \\
\text { Semi-urban (1) vs. otherwise (0) }\end{array}$ & Categorical & Observation \\
\hline
\end{tabular}




\begin{tabular}{|c|c|c|c|}
\hline & Urban vs. otherwise (0) & & \\
\hline 26. Pedal oedema & Presence of pedal oedema on both feet & Categorical & Observation \\
\hline 27. Vaccination update & $\begin{array}{l}\text { Assessment of whether vaccinations for each child } \\
\text { is updated. }\end{array}$ & Categorical & Health card \\
\hline & Mother's current HIV status & Categorical & Health card \\
\hline 29. Age in months at assessment & Age in months at time of data collection & Continuous & Health card/interview of caregiver \\
\hline 30. Birthweight & Weight as recorded in the health card & Continuous & Health card \\
\hline 31. Birth Length & Length as recorded in the health card & Continuous & Health card \\
\hline 32. APGAR Score & $\begin{array}{l}\text { Measure of the physical condition of a new-born } \\
\text { infant for heart rate, respiratory effort, muscle tone, } \\
\text { response to stimulation and skin colour. Max score } \\
=10\end{array}$ & Continuous & Health card \\
\hline 33. Age introduced complementary feeds & $\begin{array}{l}\text { Age in months first started on other foods besides } \\
\text { milk. }\end{array}$ & Continuous & Health card/interview of caregiver \\
\hline 34. Number of servings of Tsabana ${ }^{2}$ per week & $\begin{array}{l}\text { Frequency of servings of Tsabana regardless of } \\
\text { serving size per week. }\end{array}$ & Continuous & 24 hour dietary recall \\
\hline $\begin{array}{l}\text { 35. Number of consultations for diarrhoea (health } \\
\text { card) }\end{array}$ & $\begin{array}{l}\text { Frequency of consultation of diarrhoea as recorded } \\
\text { in the health card in the previous month. Counted } \\
\text { as one consultations per each date. }\end{array}$ & Continuous & Health card \\
\hline $\begin{array}{l}\text { 36. Number of days with episode of diarrhoea } \\
\text { (caregiver) }\end{array}$ & $\begin{array}{l}\text { Number of days with diarrhoea as recalled by the } \\
\text { caregiver in the previous month. }\end{array}$ & Continuous & Interview of caregiver \\
\hline 37. Number of feeds given yesterday & $\begin{array}{l}\text { Frequency of feeds solid, semi-solid or soft food } \\
\text { received during the previous day }\end{array}$ & Continuous & 24 hour dietary recall \\
\hline 38. Energy intake & $\begin{array}{l}\text { Energy intake as determined from the } 24 \text { hour } \\
\text { dietary intake recall. }\end{array}$ & Continuous & 24 hour dietary recall \\
\hline 39. Protein intake & $\begin{array}{l}\text { Protein intake as determined from the } 24 \text { hour } \\
\text { dietary intake recall. }\end{array}$ & Continuous & 24 hour dietary recall \\
\hline
\end{tabular}




\begin{tabular}{|c|c|c|c|}
\hline 40. Mother's age at birth & $\begin{array}{l}\text { The age that mother was when she gave birth to the } \\
\text { infant. }\end{array}$ & Continuous & Health card/interview of caregiver \\
\hline 41. Number of children mother has & The number of children the mother has & Continuous & Interview of caregiver \\
\hline 42. Mother's current age & Mother's current age & Continuous & Health card/interview of caregiver \\
\hline 43. Number of people in the household & $\begin{array}{l}\text { All people who resides in the household within } \\
\text { which the infant lives and who also share meals as } \\
\text { a family unit. }\end{array}$ & Continuous & Interview of caregiver \\
\hline $\begin{array}{l}\text { 44. Number of siblings/relatives living with infant } \\
\text { aged }<5 \text { years }\end{array}$ & $\begin{array}{l}\text { All infants aged }<5 \text { years currently living in same } \\
\text { home (thus sharing meals) with infant. }\end{array}$ & Continuous & Interview of caregiver \\
\hline 45. Duration mother given ZDV & $\begin{array}{l}\text { As indicated from the health card, only applicable } \\
\text { in HIV-positive mothers. }\end{array}$ & Continuous & Health card \\
\hline
\end{tabular}

Abbreviations: HEU: HIV-exposed-uninfected, HUU: HIV-unexposed-uninfected; WAZ: Weight for Age; LAZ: Length for Age; WLZ: Weight for Length; APGAR (Appearance, Pulse, Grimace, Activity and Respiration). APGAR test is usually given to a baby twice, a minute after birth and then five minutes after birth.

Tsabana: a sorghum based cereal, with added soya blend and micronutients. Provided to infants aged 6-36 months in governemnt health facilites as a way of improving the nutritional intake of infants during weaning. 